\title{
EL ENCUENTRO ENTRE OLIVARES Y LOS BANQUEROS CONVERSOS PORTUGUESES (1625-1628)
}

\author{
Carlos Javier Carlos Morales \\ (Instituto Universitario La Corte en Europa-Universidad Autónoma de Madrid) \\ carlos.carlos@uam.es
}

\section{RESUMEN}

En esta ponencia se trata sobre un aspecto de la relación que se desarrolló entre la Real Hacienda de Felipe IV y los banqueros portugueses que, en su mayor parte de origen judeoconverso, contribuyeron a la financiación del gasto dinástico durante su reinado. Tras un repaso historiográfico actualizado, se intenta precisar y, en la medida de lo posible, aportar algunos datos novedosos sobre la llegada de los banqueros conversos portugueses a la Corte, coincidiendo con la crisis del crédito que tuvo lugar en torno a 1627 y la promulgación de diversas medidas de relajación de la presión inquisitorial, presumiblemente auspiciadas por Olivares. Entre sus consecuencias, veremos las implicaciones que tuvo para la economía castellana y para las relaciones financieras internacionales.

PALABRAS CLAVE: Felipe IV; banqueros portugueses; Olivares; Inquisición; financial devolution; globalización.

\section{THE ENCOUNTER BETWEEN OLIVARES AND THE CONVERS PORTUGUESE BANQUERS (1625-1628)}

\begin{abstract}
This paper adresses an aspect of the relationship that was developed between the Royal Treasury of Philip IV and the portuguese bankers who, mostly of jew convert origin, contributed to the financing of dynastic spending during his reign. After an updated historiographic review, so that we try to specify and provide some new information on the arrival of Portuguese convert bankers to the court of Philip IV, coinciding with the credit crisis that took place around 1627 and the enactment of various measures of relaxation of inquisitorial pressure, presumably sponsored by Olivares. Among its consequences, we will see the implications it had for the Castilian economy and international financial relationships.
\end{abstract}

KEY WORDS: Felipe IV; Portuguese bankers; Olivares; Inquisition; financial devolution; globalization. 
En el presente seminario, dedicado a estudiar y comparar los fundamentos del poder de las monarquías de España y Portugal en los tiempos modernos, no podía faltar una ponencia dedicada a la relación que se desarrolló entre Felipe IV y los banqueros portugueses que, en su mayor parte de origen judeoconverso, contribuyeron a la financiación del gasto dinástico durante su reinado. Se trata de un tema tan complejo como sugerente, que desde el siglo XIX ha suscitado la atención de historiadores y hebraístas interesados por la naturaleza y características del «problema converso» (Adolfo de Castro, Amador de los Ríos, Menéndez y Pelayo, C. Lea, Adler, Azebedo...). Por nuestra parte, en esta ponencia nuestro objetivo se centra en precisar y, en la medida de lo posible, aportar algunos datos novedosos sobre la llegada de los banqueros conversos portugueses a la corte de Felipe IV, coincidiendo con la crisis del crédito que tuvo lugar en torno a 1627 y la promulgación de diversas medidas de relajación de la presión inquisitorial.

\section{UNA SIMBIOSIS COMPLICADA: CAPITAL MERCANTIL PORTUGUÉS, GASTOS DINÁSTICOS, Y SANTO OFICIO}

Como decíamos, se trata de un tema extensamente tratado y que ha conservado su vigor historiográfico, por lo que nos parece pertinente comenzar con un breve repaso actualizado del contenido de las principales obras publicadas exclusivamente desde mediados del siglo XX hasta los tiempos recientes. Por un lado, nos encontramos con una tradición historiográfica que hace bastantes décadas se preocupó de estudiar a los banqueros portugueses desde la perspectiva de su condición de judeoconversos que se introdujeron y se asentaron en la corte y en otros lugares de España, y que sufrieron por este motivo numerosos y severos procesos inquisitoriales en tiempos de Felipe IV. Entre los especialistas españoles en el tema de las minorías religiosas, su persecución, y su significado histórico, podemos citar a dos insignes autores.

En la tesitura historiográfica de los años cincuenta, don Antonio Domínguez Ortiz completó a fin un sugerente trabajo sobre la caracterización social de los conversos, en el que nos encontramos una interpretación sobre lo que denominó «Política filohebrea del Conde Duque» que merece ser citada:

Olivares sabía por experiencia que los arrendadores de rentas, banqueros y asentistas, de los que la Hacienda Real necesitaba, no se podían reclutar en Castilla; no había más alternativa que entregarse en manos de alemanes e italianos o de marranos portugueses; todos eran igualmente ávidos, pero los portugueses tenían desde el punto de vista español la ventaja de ser vasallos del mismo monarca, por lo cual las sumas que ganasen con sus transacciones no podían considerarse perdidas. Movido por esta consideración reanudó la política de Felipe III en los primeros años de su reinado y sin cuidarse del efecto que produciría en Portugal les concedió, por Real cédula de 17 
de noviembre de 1627, libertad de movimiento, e incluso les autorizó a disponer libremente de sus bienes ${ }^{1}$.

Precisamente, Domínguez Ortiz, en unas breves páginas de su Política y Hacienda de Felipe IV, cuya primera edición vio la luz en 1960, insistió en este vínculo entre el mundo de los hombres de negocios conversos portugueses y la Real Hacienda de Felipe IV como una de las características singulares del reinado, con la labor de la Inquisición como un factor con una influencia determinante ${ }^{2}$. Don Antonio, años después, en 1971, en otro estudio clásico, abundó sobre «la entrada de los marranos portugueses en Castilla y sus consecuencias», reiterando la interpretación de estos datos ya aportados con anterioridad ${ }^{3}$.

Mientras tanto, Julio Caro Baroja había publicado a comienzos de la década de los sesenta varios estudios fundamentales para la historia de los judíos y conversos en España, en los que mostraba los fundamentos de la presencia de los cristianos nuevos portugueses dedicados a la contratación financiera con el apoyo de Olivares, una posición que no les evitó sufrir severos procesos inquisitoriales, como fue el caso de los banqueros Juan Núñez Saravia, en 1632-1637, y, posteriormente, ya a mediados del siglo XVII, de Francisco Díaz Méndez Brito, Francisco López Pereira, y Manuel Cortizos, entre otros ${ }^{4}$.

Así pues, tanto en Caro Baroja como en Domínguez Ortiz encontramos la idea de que, necesitado de recursos financieros, fue Olivares el instigador de la presencia de los banqueros portugueses en la Corte, para lo que no dudó en protegerles con edictos de gracia y de licencias, a pesar de lo que posteriormente algunos fueron objeto de procesamiento y castigo por parte del Santo Oficio. En ese sentido, no podemos dejar de citar también que en aquellos años se llevó a cabo la traducción y primera edición de una sugerente obra de Yerushalmi, que dotó de nuevas perspectivas al estudio de la introducción de los judeoconversos portugueses y del marranismo en la España del siglo XVII ${ }^{5}$.

Por su parte, los historiadores de las finanzas regias también habían avanzado en el conocimiento del tema desde su propia perspectiva historiográfica. En 1970, don

\footnotetext{
${ }^{1}$ Antonio Domínguez Ortiz, La clase social de los conversos en Castilla en la Edad Moderna, (Madrid, 1955), 110-111. Una valoración historiográfica de su obra, en Jaime Contreras Contreras, "Domínguez Ortiz y la historiografía sobre judeoconversos", Manuscrits 14 (1996): 59-80.

2 Antonio Domínguez Ortiz, Política y Hacienda de Felipe IV, (Madrid: Pegaso, 1960), 121-133.

3 Antonio Domínguez Ortiz, Los judeoconversos en España y América, (Madrid: Istmo, 1971), 59-75. También, J. I. Pulido Serrano, “Antonio Domínguez Ortiz y el problema converso en su obra”, Historia Social, 47 (2003): 53-69.

${ }^{4}$ Julio Caro Baroja, Los judios en la España moderna y contemporánea, 3 vols., (Madrid: Arión, 1961-1962), (manejo la $3^{\text {a }}$ edición, 3 vols, Madrid: Itsmo, 1986, tomo II, caps. 3-6), y La sociedad criptojudía en la Corte de Felipe IV (Madrid, 1963); hemos manejado la versión publicada en Inquisición, brujería y criptojudaísmo (Madrid: Ariel, 1974), 11-180. Una valoración de su obra, J. I. Pulido Serrano, "Los judíos en la obra de Julio Caro Baroja", Historia Social 55 (2006): 45-60.

${ }^{5}$ Yosef Hayin Yerushalmi, De la Corte española al gueto italiano. Marranismo y judaísmo en la España del siglo XVII. El caso Isaac Cardoso, (Madrid, 1971), para lo que nos interesa, especialmente, cap. 1 (manejo la segunda edición, Madrid: Turner, 1989).
} 
Felipe Ruiz Martín vinculó la introducción de los portugueses con el desgaste de los hombres de negocios de Génova y de sus redes de Italia y el Mediterráneo, y con el fin de su hegemonía sobre las finanzas castellanas como consecuencia de la crisis de deuda de 1627. Dos décadas más tarde, con ocasión de su discurso de entrada en la Academia de la Historia, Ruiz Martín, hizo uso de estos conocimientos y precisó la forma en que a partir de esta fecha genoveses y portugueses y alemanes compartieron la financiación de la Real Hacienda 6 .

Para entonces, ya habían aparecido nuevas publicaciones sobre esta relación triangular entre Inquisición, Felipe IV, y banqueros portugueses. En 1978, en la Universidad de California (Berkeley), se defendió una tesis doctoral firmada por James Boyajian, sobre el protagonismo de los banqueros portugueses en la formación y expansión de la economía atlántica, que sería la semilla de varios trabajos de este autor ${ }^{7}$. El primero que vio la luz editorial, en 1983, procuró insertar esta labor de crédito al servicio del Felipe IV como un aspecto del desarrollo de los mercados internacionales y de lo que denominó atlantic paysystem, en contraste con el dominio genovés sobre las ferias de Piacenza ${ }^{8}$. A lo largo de las páginas de este libro desfilan los banqueros conversos portugueses que, asentados en la Corte y conectados con los mercados financieros, permitieron a Felipe IV disfrutar de lo que Boyajian denominó Financial Miracle, entre 1631 y 1640 . A su juicio, resultaba patente el vínculo entre la presencia en Castilla de los hombres de negocios portugueses de origen converso, las necesidades financieras de Felipe IV para hacer frente a las guerras europeas, y la expansión de la economía internacional tanto en el Atlántico como en el Pacífico.

Esta línea de investigación sobre los hombres de negocios judeoconversos portugueses y sus redes comerciales mantuvo continuidad en esta década de 1980 gracias a un joven estudiante holandés prematuramente fallecido, en un breve pero interesante trabajo surgido de su memoria de licenciatura ${ }^{9}$. En sus conclusiones, Broens señaló que las rutas comerciales actuaban como arterias financieras de la Monarquía, y situó la llegada de los conversos portugueses en la nueva orientación de España dentro de la economía atlántica, como colaboradores imprescindibles para el esfuerzo político y militar llevado a cabo entre 1621 y 1639, gracias a sus contactos en Castilla, Ruan y Nantes, Amberes, Amsterdam, Hamburgo y otras ciudades hanseática, como fue el caso de Juan Núñez Saravia y Bartolomé Febo.

Por su parte, al cabo de una década de su anterior libro, Boyajian publicó otra obra en la que expuso el dominio luso sobre el comercio internacional de especias y artículos de lujo, como una empresa en la que los comerciantes privados dispusieron de recursos que no solo estuvieron claramente por encima de los aportados por su

\footnotetext{
${ }^{6}$ Felipe Ruiz Martín, “La banca en España hasta 1782”, en El Banco de España. Una historia económica. (Madrid, 1970), 97-101, 115-121, y Las finanzas de la monarquia hispánica en tiempos de Felipe IV, (Madrid, 1990), 66-67, passim.

7 James C. Boyajian, The Portuguese Bankers and the International Payments Mechanism, 1626-1647, (Berkeley, 1978).

${ }^{8}$ James C. Boyajian, Portuguese bankers at the court of Spain, 1620-1650, (New Brunswick, 1983).

${ }_{9}^{9}$ Nicolas Broens, Monarquia y capital mercantil: Felipe IV y las redes comerciales portuguesas (1627-1635), (Madrid, 1989).
} 
Corona, sino que incluso superaron a los de la compañía holandesa más grande de las Indias Orientales ${ }^{10}$. El comercio portugués-asiático formó parte de una red comercial global que unía a Europa, Asia y también, por primera vez, a África occidental y Brasil, y casi la mitad de las operaciones estuvieron controladas por mercaderes de origen cristiano nuevo. Irónicamente, concluye Boyajian, la gran riqueza que fluyó hacia Portugal entre 1580 y 1640 hizo poco para enriquecer al país, ya que los aristócratas terratenientes que controlaban la Iglesia, la Inquisición y la administración real utilizaron su posición para negar a los comerciantes conversos la posición social que les pudo haber alentado para realizar inversiones productivas en su propio reino. Esto tuvo varias consecuencias correlativas: una, la salida de capitales de los hombres de negocios conversos hacia la financiación de la Monarquía Católica, otra, el avance holandés en Asia, que con el paso de los años efectivamente cortaría la hegemonía portuguesa.

Por consiguiente, la entrada de los hombres de negocios lusos en Castilla se comprendía como una conexión de la economía internacional con las necesidades financieras de la Monarquía Católica, lo que no podía dejar de tener consecuencias para la economía y la sociedad castellanas. Precisamente, este mismo año fue publicado un breve artículo por el profesor Ebben, en el que abordó el significado de las complejas relaciones que surgieron y se desarrollaron en tiempos de Felipe IV entre los banqueros portugueses de origen judeoconverso, el Santo Oficio, y la monarquía católica ${ }^{11}$. Al cabo de unos años, Ebben publicó una obra fruto de su tesis doctoral, cuyo punto de partida se encontraba en un interrogante fundamental: ¿cómo consiguió Castilla ser el centro del Imperio y convertirse en su pulmón financiero y sostener sus gastos bélicos durante décadas en territorios tan dispersos y lejanos? La clave estuvo en los banqueros que, desde los tiempos de Carlos V, negociaron créditos a cambio de rentas, por lo que dentro de este proceso secular resultaba pertinente profundizar en la participación de los conversos portugueses en las operaciones financieras durante el reinado de Felipe $\mathrm{IV}^{12}$. Tal obra comprendía estas relaciones como parte de la expansión del capitalismo atlántico y, aunque remarcó que este sentido que «was logical in financial and logistical respects, but socially it was not», a causa de su condición religiosa. Los motivos de persecución fueron diversos, sin duda, religiosos, pero también encontramos ingredientes de xenofobia y antisemitismo, como en los escritos de don Francisco de Quevedo. Así que en distintos niveles y formando parte de generaciones solapadas gracias a sus redes familiares los conversos procedentes de Portugal actuaron expandiendo sus servicios a la Corona como comerciantes, arrendadores de rentas reales, y, en la cúspide, como asentistas, si bien carecían de salvaguarda respecto al Santo Oficio.

${ }^{10}$ James C. Boyajian, Portuguese Trade in Asia Under the Habsburgs, 1580-1640, (Baltimore, 1993).

11 Maurits Ebben, "Un triángulo imposible: la Corona española, el Santo Oficio y los banqueros portugueses, 1627-1655”, en Hispania 184 (1993): 541-556.

12 Maurits Ebben, Zilver, brood en kogels voor de Koning. Kredietverlening door Portugese bankiers aan de Spanase Kron 1621-1665, (Leiden, 1996) (que podemos traducir como Plata, pan y balas para el rey. Préstamos de banqueros portugueses a la Corona española). 
Entretanto, los historiadores de las finanzas de Felipe IV avanzaban en el conocimiento de la participación de los portugueses en su condición de hombres de negocios. Unos años antes, Carmen Sanz, en su obra sobre los banqueros de Carlos II arrancaba en realidad de mediados del siglo XVII, y expuso la participación y trayectoria de la última generación de banqueros portugueses, que operaron a partir de $1650^{13}$. Por su parte, Álvarez Nogal dedicaba un estudio a referir las fases de la negociación financiera en el reinado de Felipe IV y a trazar la trayectoria de los asentistas que cobraron consignaciones en la Casa de Contratación, en el que encontramos a una amplia nómina de marranos portugueses, como Duarte Fernández, Jorge de Paz Silveira, Manuel de Paz y Fernando Tinoco, Simón y Lorenzo Pereira, Simón Suárez Dorta, Nuño Díaz Méndez Brito, Marcos Fernández Monsanto, y, por supuesto, los hermanos Cortizos ${ }^{14}$.

De forma complementaria, desde la otra perspectiva, entre finales del siglo pasado y los primeros años del presente se produjo una cierta renovación de los estudios sobre el marranismo y los principales hombres de negocios conversos portugueses que medraron en la corte de Felipe IV gracias a varias investigaciones elaboradas en la Universidad de Alcalá de Henares bajo el patrocinio del Instituto Internacional de Estudios Sefardíes y Andalusíes. En primer lugar, cabe señalar al profesor Pulido Serrano, cuya tesis doctoral, presentada en 1999 y publicada en 2002 con un sugerente título, indagaba en las razones del antijudaísmo en el siglo XVII, la actuación de la Inquisición, y algunos de los procesos inquisitoriales que tuvieron lugar en Madrid, y en la que se encuentra un extenso capítulo en el que trata sobre la política relativa a los cristianos nuevos portugueses en el reinado de Felipe IV, que comienza con el mito del filohebraísmo de Olivares ${ }^{15}$.

En segundo lugar, tenemos que citar la tesis doctoral de López Belinchón, en la que estudió la inserción en la economía castellana y en la Hacienda Real de Fernando de Montesinos, un converso luso de ascendencia castellana de la familia López Téllez, que de joven cambió de nombre para escapar inicialmente de la Inquisición, lo que no le evitó un segundo proceso entre 1632 y $1637^{16}$. Así, de un lado, esta obra nos permite

\footnotetext{
${ }^{13}$ Carmen Sanz Ayán, Los banqueros de Carlos II, (Madrid, 1988), 163-168 y 336-376, y también "Las finanzas de la Monarquía y los banqueros judeoconversos. Una aproximación a los sistemas ordinarios de financiación de la corona en el reinado de Felipe IV", en Xudeus e conversos na historia, ed. C. Barros, 2 vols., (Santiago de Compostela, 1994), II, 185-200.

${ }^{14}$ Carlos Álvarez Nogal, Los banqueros de Felipe IV y los metales preciosos americanos (1621-1665), (Madrid, 1997), 89-108.

${ }^{15}$ I. Pulido Serrano, Injurias a Cristo. Religión, política y antijudaísmo en el siglo XVII, (Madrid, 2002), 37108. Posteriormente, otros trabajos de síntesis que resultan de indudable interés: Los conversos en España y Portugal, (Madrid, 2003), y, más reciente, "El tiempo de los portugueses. Cristianos nuevos, judaizantes e inquisición (siglos XVI-XVII)", en La inquisición: viejos temas, nuevas lecturas, coords. Manuel Peña Díaz y Jaqueline Vassallo, (Córdoba, 2015), 233-253.

${ }^{16}$ Bernardo López Belinchón, Honra, libertad y hacienda (hombres de negocios y judíos sefardíes), (Madrid, 2001). También, del mismo, "Olivares contra los portugueses. Inquisición, conversos y guerra económica" en Historia de la Inquisición en España y América, 3 vols., J. Pérez Villanueva. y B. Escandell Bonet, (Madrid, 2000), III, 499-530.
} 
conocer la forma en que funcionaba una casa comercial, sus redes familiares, sus negocios lícitos y de contrabando, y cómo gracias a esta medranza económica Montesinos finalmente se convirtió en banquero, arrendador de rentas locales y reales, y asentista de Felipe IV. De otro lado, tras repasar la «relación de muto interés» que surgió entre la Corona y los negociantes judeoconversos durante las primeras décadas del siglo XVII, tilda de «amistad peligrosa» la que mantuvieron con Olivares, ya que el valido no dudó en utilizar sus habilidades financieras sin que esto fuera óbice para que en otras ocasiones recurriera a la Junta del Almirantazgo y a la Inquisición para reprimir las actividades de contrabando que nutrían de beneficios a los portugueses.

Finalmente, el profesor Jesús Carrasco centraba su tesis doctoral, presentada en 2004, en, acaso, dos de los más conocidos hombres de negocios conversos portugueses del primer tercio del siglo XVII, Juan Núñez Correa y su sobrino Juan Núñez Saravia, quien asumió tras la muerte del primero en 1625 la dirección del negocio familiar y participó activamente en las importantes operaciones de crédito que tuvieron lugar entre 1626 y 1632, cuando hubo de retirarse al ser procesado por el Santo oficio ${ }^{17}$. En suma, estas tesis y las publicaciones resultantes significaron un impulso indudable en el conocimiento del universo judeoconverso portugués y sus relaciones con la Corona y con la Inquisición.

Con este bagaje historiográfico resulta comprensible que el tema haya mantenido su vigencia y que, durante los últimos años, se hayan producido nuevas aproximaciones por parte de jóvenes historiadores. Así, entre los interesados por su condición de minoría religiosa perseguida podemos resaltar la tesis doctoral de Cañas Pelayo sobre la actuación del tribunal inquisitorial en el distrito de Córdoba ${ }^{18}$, mientras que, para el tema de la relación entre el Santo Oficio, los banqueros portugueses y Olivares, encontramos algunos trabajos de Shai Cohen ${ }^{19}$.

Por otra parte, desde la perspectiva de las historia de las finanzas de Felipe IV, recientemente la profesora Sanz Ayán ha publicado una magnífica obra, en la que se pregunta por las relaciones que tuvieron los grandes financieros con el poder y con Olivares y su papel en la situación política y en las rebeliones de la década de 1640: en su primera parte, al tratar del sistema crediticio, para referir la posición de los portugueses retoma una frase de Quevedo, «caudal pronto y crédito puntual», que le

\footnotetext{
17 Jesús Carrasco Vázquez, La minoría judeoconversa en la época del conde duque de Olivares. Ange y ocaso de Juan Núnez. Saravia (1585-1639), Tesis doctoral (en acceso abierto) (Universidad de Alcalá, 2004). Más adelante citaremos otros trabajos del mismo.

18 Marcos Rafael Cañas Pelayo, Los judeoconversos portugueses en el Tribunal Inquisitorial de Córdoba: Un análisis social (ss. XVI-XVII), Tesis doctoral (en acceso abierto), (Universidad de Córdoba, 2016). Una parte de la misma, en "Los judeoconversos portugueses de la edad moderna en la historiografía española: un estado de la cuestión”, en Revista de Historiografía 23 (2015): 217-243.

${ }^{19}$ Shai Cohen, "Los banqueros portugueses, potestad económica versus autoridad divina", en El universo simbólico del poder en el Siglo de Oro, eds. Á. Baraibar y M. Insúa, (Univ. de Navarra, 2012), 51-63; y "El retorno de los judeoconversos portugueses en época del conde duque de Olivares", en Hipogrifo: Revista de Literatura y Cultura del Siglo de Oro, vol-extr. 1 (2018): 191-215. No hemos podido consultar su tesis doctoral, presentada en la Universidad de Navarra en 2014: Poder, Sangre y Dinero: Olivares en su laberinto, en la que se estudia el tema desde el punto de vista literario y discursivo (no disponible en acceso abierto).
} 
sirve para explicar cumplidamente la inserción de los comerciantes y financieros judeoconversos en la economía atlántica, sus redes internacionales, sus ámbitos de negocio, y los orígenes de su penetración en Castilla tras la anexión de Portugal en 1580 y su posterior enraizamiento en las primeras décadas del siglo XVII ${ }^{20}$. Más adelante, en su análisis de la evolución del crédito en los años cuarenta, relaciona la gradual primacía de los portugueses con el retraimiento de los banqueros genoveses, de manera que, en la tercera parte, al tratar sobre los protagonistas de la financiación expone que desde 1632 dos portugueses judeoconversos se situaron y se mantuvieron en la cima de la contratación financiera, Jorge de Paz Silveira y Duarte Fernández de Acosta, a los que posteriormente se unieron Duarte Brandon Suárez y Fernando Tinoco.

Así mismo, desde esta óptica del análisis de biografías sobre estos personajes contamos con dos breves trabajos sobre el citado hombre de negocios portugués más importante de dicho período, Jorge de Paz Silveira, que demuestran la complejidad de los intereses de este miembro de la elite financiera ${ }^{21}$. Finalmente, entre las últimas aportaciones al tema tenemos que citar a otro joven doctorando, Álvaro Sánchez Durán, que está dando un enfoque renovador al estudio de las actividades, familias, movilidad social y redes de los hombres de negocios conversos portugueses en Castilla $^{22}$. En particular, en un reciente trabajo se ha dedicado al análisis de las relaciones cortesanas y contratos de una familia de financieros judeoconversos portugueses durante el reinado de Felipe IV, los Núñez-Mercado, afectada por la suspensión de pagos de 1647 y por las persecuciones inquisitoriales de esta década ${ }^{23}$.

En definitiva, podemos afirmar que disponemos de un considerable volumen de información sobre la naturaleza y fundamentos, el origen y fases de la presencia y actividades de los hombres de negocios portugueses en la corte de Felipe IV. Por mi parte, ya que en varios trabajos he procurado analizar la evolución de la política

${ }^{20}$ Carmen Sanz Ayán, Los banqueros y la crisis de la Monarquía hispánica de 1640, (Madrid, 2013), 40-60, etc.

${ }^{21}$ Roberto García Puente, "Colaboración e intereses entre la monarquía de Felipe IV y los hombres de negocios de la nación portuguesa Jorge de Paz Silveira y Pedro de Baeza”, en Familia, Cultura Material y Formas de Poder en la España Moderna, Máximo García Fernández, (Madrid, 2016), 1191-1199; y Cristina Hernández Casado, "El negocio de los asientos: Jorge de Paz Silveira, financiero portugués al servicio de Felipe IV", en Monarquias en conflicto. Linajes y noblezas en la articulación de la monarquia hispánica, coords. José I. Fortea Pérez et allii, (Madrid, 2018), 441-450.

22 Álvaro Sánchez Durán, "Los hombres de negocios portugueses: una élite profesional en la Castilla del siglo XVII. Posibilidades de movilidad social e intermediación", en Tiempos modernos 31 (2015/2): 193-220, "Información y reputación en el siglo XVII: la construcción de la confianza en redes sociales de hombres de negocios portugueses", en Studia histórica. Historia moderna 38-2 (2016): 425-466, "Familia, parentesco y estrategias matrimoniales: hombres de negocios de la nación portuguesa en la corona de Castilla (siglo XVII)", en Nuevas perspectivas de investigación en Historia Moderna: Economía, Sociedad, Política y Cultura en el Mundo Hispánico, eds. Ma Ángeles Pérez Samper y José L. Betrán Moya, (Madrid, 2018). También, "Imbricaciones entre lo público y lo privado en la gestión de la Real Hacienda de Felipe IV: hombres de negocios portugueses y ministros reales", en Palacios, plazas, patíbulos. La sociedad española moderna entre el cambio y las resistencias, James Amelang et allii, (Valencia, 2018), 447-460.

23 Álvaro Sánchez Durán, "El crédito portugués en la Monarquía Hispánica de Felipe IV: los asientos de la familia Núñez-Mercado (1640-1652)”, en Cuadernos de historia moderna 42, 1 (2017): 57-86. 
financiera durante la primera década del reinado de Felipe IV, considero que resulta pertinente centrar mi exposición en explicar cómo se produjo el encuentro entre Olivares y los hombres de negocios de la nación portuguesa en el contexto de la crisis financiera de 1627 y relacionarlo con la evolución de los mecanismos de financiación de la Real Hacienda durante la guerra de los Treinta Años ${ }^{24}$.

\section{LA LLEGADA DE LOS PORTUGUESES A LA CORTE DE FELIPE IV Y LA CRISIS FINANCIERA DE 1627}

Tal y como en las referencias anteriores hemos recogido, los portugueses que a partir de 1626 se incorporaron a la financiación de la Monarquía tenían bastantes rasgos generacionales comunes. Durante el siglo XVI un pequeño y cerrado círculo de familias lisboetas había controlado el comercio de la pimienta y las especias, creando ramificaciones en Amberes, Florencia y Venecia, hasta que, como consecuencia de la competencia holandesa e inglesa y de la pérdida de mercados se retiraron de estos tráfagos. Una nueva generación de mercaderes portugueses de origen converso, nacidos en torno a 1580, emergió al socaire del comercio de exóticos y lujosos productos procedentes de China, Japón, India y otros territorios tanto asiáticos como africanos (seda, joyas y piedras preciosas, perfumes, porcelanas, etc). En el Atlántico, este circuito se entrelazaba con el comercio del azúcar brasileño y con el tráfico de los esclavos africanos llevados por los portugueses al continente americano. Goa y Macao, Pernambuco, las costas africanas, conectaban con Europa a través de Lisboa, desde donde las redes y los productos se extendían por Sevilla y otras ciudades portuarias del continente europeo. Los beneficios en oro y plata eran cuantiosos y les daban una posición fundamental en el mercado de Ámsterdam y en otras plazas europeas, en donde contaban con familiares y amigos ${ }^{25}$.

Aunque para Israel «la fácil entrada de los marranos portugueses en España se explica por la ausencia de una fuerte clase empresarial autóctona», considero que la cuestión no es tan sencilla y estuvo relacionada con otros factores ${ }^{26}$. Se trataba de reputados hombres de negocios con contactos internacionales, que, además, en algunos casos disfrutaban de puestos en la casa real y en otras instituciones del reino luso, cuya participación en la financiación de la Monarquía Católica no se produjo de manera improvisada o casual.

\footnotetext{
${ }^{24}$ Carlos Javier de Carlos Morales, El precio del dinero dinástico: endeudamiento y crisis financieras en la España de los Austrias, 1557-1647, 2 vols., (Madrid, 2016), I, 167-192, "La política financiera de Felipe IV, 1621-1628”, en La Corte de Felipe IV (1621-1665). Reconfiguración de la Monarquía católica. III. El sistema de corte. Consejos y Hacienda, 4 vols., José Martínez Millán y Manuel Rivero, (Madrid, 2017), vol. 2, 10991212, "Financiando la Guerra de los Treinta Años: gasto bélico, endeudamiento dinástico y financial devolution”, en Manuscrits. Revista d'Història Moderna 38 (2018): 109-138.

${ }^{25}$ Se trata de un tema con una bibliografía muy extensa, por lo que nos limitaremos a citar las síntesis de Boyajian, Portuguese bankers, 4-16; y con más amplitud, Daviken Studnicki-Gizbert, $A$ nation upon the ocean sea Portugal's Atlantic diaspora and the crisis of the Spanish Empire, 1492-1640, (Oxford-New York Oxford, 2007).

${ }^{26}$ Jonathan Israel, La judería europea en la era del mercantilismo (1550-1750), (Madrid, 1992), 82.
} 
Según se afirma conmúmente, los conversos portugueses aprovecharon la coyuntura financiera de los Austrias para intentar mejorar sus condiciones respecto a la Inquisición portuguesa. En pleno esfuerzo bélico de los inicios del reinado de Felipe III, obtuvieron los decretos de 1601, por el que el rey accedió a conceder su libertad de movimientos entre Portugal y la Monarquía, y de enero de 1605, que significó un Perdón General ${ }^{27}$. Sobre la consecución de estos decretos y la introducción de los banqueros lisboetas en la corte de Felipe III actualmente disponemos de un jugoso trabajo de Pulido Serrano que muestra cómo los principales hombres de negocios de Lisboa «de la nación» enviaron un comisionado para que negociara el perdón y la libertad de movimientos, a cambio de un importante donativo y de sobornos y cohechos a Lerma, Franqueza, y otros consejeros del rey ${ }^{28}$. Aunque en 1610 se revocaría la libertad decretada en 1601 por la que los cristianos nuevos podían abandonar Portugal sin licencia, las anteriores facultades habían despejado un camino iniciado en 1580, con el que consiguieron abrir el acceso a Sevilla y Madrid y otras ciudades castellanas en las que proliferaban las actividades comerciales, y participar activamente bajo la protección de Lerma en los tráfagos derivados de la expulsión de los moriscos, el arrendamiento de rentas aduaneras y la compra y exportación de lana 29.

Así pues, a finales del reinado de Felipe III los hombres de negocios portugueses disponían de dos cualidades sumamente valiosas que les ponía en una posición singular para colaborar con la financiación de los gastos dinásticos de la Monarquía y competir con los genoveses: stock de capital, crédito y redes familiares y territoriales en los mercados de Lisboa, Ámsterdam y otras plazas europeas; y conexión con los distintos agentes y ámbitos mercantiles y hacendísticos de la Corona de Castilla.

${ }_{27}$ Para este tema, citamos la obra más reciente, de Ana Isabel López-Salazar Codes, Inquisición portuguesa y monarquía hispánica en tiempos del perdón general de 1605, (Évora, 2016), cap. 1.

${ }^{28}$ Con detalle, Juan I. Pulido Serrano, "Las negociaciones con los cristianos nuevos en tiempos de Felipe III a la luz de algunos documentos inéditos (1598-1607)”, en Sefarad 66-2 (julio-diciembre 2006): 345-376. El personaje se acompañó, además, de 200.000 ducados con los que se dedicó a sobornar a los principales cortesanos, comenzando por el propio Lerma. La propuesta de momento fue rechazada por el Consejo de Estado, pero en 1601 «los hombres de la nación más ricos y más honrados», volvieron a enviar a dos procuradores, que ofrecieron hasta 800.000 ducados por el perdón general. Aunque este no se produjo todavía, de momento consiguieron que ese mismo año Felipe III decretara la libertad de movimientos de los conversos portugueses. Las negociaciones continuaron, de la mano de Pedro Franqueza, hechura de Lerma, y miembro de la junta de Hacienda de Portugal y de la Junta del desempeño General. En 1604 Afonso Gomes llegó a Valladolid, en donde se encontraba la corte, con poderes de algunos cristianos nuevos portugueses para repartir sobornos entre Lerma y otros ministros de Felipe III. Pedro Franqueza convenció a Gomes para que aumentara la cantidad hasta 1.700.000 ducados, que fue la suma pactada finalmente con Lerma, gratificaciones aparte (Franqueza recibió 86.000 ducado) El Perdón General fue publicado en Lisboa en enero de 1605.

${ }^{29}$ Carrasco Vázquez, La minoría judeoconversa, 168-229, y "El relevante papel económico de los conversos portugueses en la privanza del duque de Lerma (1600-1606)", comunicación presentada al XXV Encontro da APHES, Évora 10-19 de noviembre de 2005; Máximo Diago Hernando, "La irrupción de los conversos portugueses en el comercio de exportación de lanas de la Corona de Castilla en el tránsito del siglo XVI al XVII", en Sefarad 70-2 (julio-diciembre, 2010): 399-434. Un ejemplo muy significativo y documentado sobre esta medranza económica diversificada, Pilar Huerga Criado, Manuel Enríquez: Un cristiano nuevo entre los poderosos, (Ciudad Rodrigo, 2001). 
Sobre esta base, a partir de 1618 los judeoconversos portugueses retomaron el envío de memoriales al rey y a su confesor solicitando que se reestableciera su libertad de movimientos; al mismo tiempo, sesudos arbitristas, alguno vinculado a la Inquisición, como González de Cellorigo, razonaban la conveniencia de suavizar el rigor del Santo Oficio y facilitar la colaboración de los marranos en la recuperación económica de la Monarquía Católica ${ }^{30}$. Otros memorialistas, como Manuel López Pereyra, portugués de origen judeoconverso que desde 1621 asesoraba a Olivares y que tuvo entrada en la Junta de Comercio creada en 1623, proponía medidas arancelarias en contra de los holandeses que redundaban, sin duda, en favor de la presencia mercantil lusa y, por ende, fortalecerían la Monarquía ${ }^{31}$. En sentido semejante se expresaba el arbitrista converso Duarte Gomes Solis, advirtiendo que una mayor participación de los portugueses redundaría en beneficio del sistema comercial de la Monarquía y serviría para frenar a sus enemigos ${ }^{32}$.

Aunque el clima de reformismo económico alentado por Olivares en los inicios del reinado de Felipe IV resultaba propicio para los conversos portugueses, la cuestión no hubo de ser fácil ni sencilla. El primer paso lo dieron a finales de 1622, cuando un grupo de mercaderes de Lisboa ofreció a Felipe IV un donativo de 150.000 ducados a cambio de un nuevo Perdón General, el derecho de libre movimiento y establecimiento en cualquier parte de la monarquía, mediante la anulación del decreto de $1610^{33}$. Pero había varios obstáculos para que la propuesta prosperara. Por una parte, durante varios años el asunto se discutió en una junta presidida por el confesor del rey, fray Antonio de Sotomayor, y la oposición del Santo Oficio portugués fue firme. Por otra parte, desde al menos 1621 los portugueses participaban no solo en negocios mercantiles legales sino también en lucrativas actividades de contrabando de moneda y otros productos de Francia y Holanda que se distribuían en Madrid y otros mercados castellanos, lo que suscitaba el recelo en la Corte y en los comerciantes de Sevilla y otras plazas ${ }^{34}$.

Desde inicios de siglo la intervención hacendística de los marranos portugueses se había extendido en el ámbito de los arrendamientos de rentas, como la avería, pero al cabo de unos años la coyuntura les resultó favorable para ampliar su actuación. La entrada en la guerra del Palatinado y el fin de la Tregua de los Doce Años significaron un aumento de los costes militares. Así, por ejemplo, cuando se elaboró la previsión

30 Pulido Serrano, Injurias a Cristo, 57-65.

${ }^{31}$ J. Israel, "Manuel López Pereyra of Amsterdam, Antwerp and Madrid: jew, nee Christian, and advisor to the conde-duque of Olivares", en Studia Rosenthaliana XIX-1 (1985): 109-126.

${ }^{32}$ Nathan Wachtel, “The 'Marrano' Mercantilist Theory of Duarte Gomes Solis”, The Jewish Quarterly Review, 101-2 (2011): 164-188.

33 Elkan N. Adler, "Documents sur les marranes d' Espagne et de Portugal sous Philippe IV”, en Revue des études juives, 48 (1904): 14-15; 49 (1905): 52, 58-59; y 50 (1905): 222-224. Según autores, la cifra oscila entre 140.000 y 250.000 ducados, confusión debida a las imprecisiones del propio Adler. La mejor sintesis para este tema, Pulido Serrano, Injurias a Cristo, 65-86.

${ }^{34}$ Jesús A. Carrasco Vázquez, "Contrabando, moneda y espionaje (el negocio del vellón (16061620)", en Hispania 197 (1997): 1081-1105, Bernardo López Belinchón, "Sacar la sustancia del reino. Comercio, contrabando y conversos portugueses, 1621-1640”, en Hispania 209 (2001): 1017-1050. 
de gastos a satisfacer mediante provisiones en 1622, Flandes pasó de 1.500 .000 a 3.600.000 escudos, y la armada del Mar Océano, de 480.000 a 1.076 .066 ducados. Como es sabido, la atención de los desembolsos dinásticos de la Monarquía se efectuaba a través del crédito y del endeudamiento, que se caracterizaron no solo como una vía de superación del déficit, sino como el eje en torno al que giraban las demás actividades hacendísticas. El cumplimiento de los principales gastos tanto militares como cortesanos se efectuaba a través de uno o varios contratos financieros, cuya estimación anual se agrupaba en el concepto de provisiones. Para alcanzar tales sumas, el Consejo de Hacienda procuraba negociar un asiento grande o de provisiones generales, generalmente con un consorcio de hombres de negocios genoveses que se repartían entre sí tanto la entrega como las consignaciones recibidas en pago, en su mayor parte sobre los diversos servicios otorgados por las Cortes, las Tres Gracias, y las remesas de Indias ${ }^{35}$.

Este incremento de los gastos bélicos pudo sostenerse gracias a un esfuerzo considerable de la Real Hacienda de Castilla y a una intensa actividad crediticia que fue asumida por los hombres de negocios genoveses y, en menor medida, alemanes, gracias a que desde 1618 la Real Hacienda había encontrado dos suculentas fuentes de financiación extraordinarias: la reanudación de la acuñación de moneda de vellón y las enajenaciones de juros. En primer lugar, la moneda de cobre fue empleada en los asientos como consignación y como licencia de importación del metal para ser acuñado; en segundo lugar, en las operaciones con los juros al quitar se encontró otro recurso adicional, gracias a una conversión forzosa del tipo de interés y del valor nominal de los juros efectuada en octubre de 1621. En suma, ambos expedientes dotaron de liquidez adicional y de fondos que fueron empleados como consignación en los asientos que durante los años siguientes se firmaron con los genoveses.

Sin embargo, con el paso de los años dichos recursos financieros se fueron depreciando (debido, entre otros motivos, al premio de la plata) y, por consiguiente, los genoveses elevaron sus exigencias para mantener los niveles de contratación crediticia $^{36}$. La Real Hacienda tuvo que abrir otras posibilidades de consignación con objeto de satisfacer los gastos crecientes, como la venta de vasallos, donativos, y nuevos servicios de millones. En esta coyuntura de dificultades crediticias de Felipe IV los marranos portugueses retomaron sus propuestas de participación en la financiación de la monarquía: para ellos, la obtención de consignaciones y el manejo de juros y de moneda de vellón a través de los asientos podía resultar un activo que se podía emplear en los negocios mercantiles y hacendísticos que desde tiempo atrás estaban desarrollando; $\mathrm{y}$, al mismo tiempo, su colaboración podría actuar como un aliciente para solicitar y conseguir una mejora de su situación respecto al Santo Oficio, como había ocurrido un par de décadas antes con Felipe III. Pero, si con Lerma la vía del donativo acompañada de sobornos había surtido efectos, con Olivares la cuestión era diferente.

\footnotetext{
35 De Carlos Morales, "La política financiera”, 1102-1107.

${ }^{36}$ De Carlos Morales, El precio del dinero, I, 175-178.
} 
En 1625, el año de Breda y Bahía, las exigencias de gasto dinástico no dieron respiro a la Real Hacienda de Castilla. El 9 de abril se abrió la espita que permitió a los banqueros portugueses sumarse al esfuerzo financiero, cuando los hermanos Simón y Lorenzo Pereira firmaron un asiento para situar en Flandes 12.000 escudos de plata en favor del conde de Gondomar, embajador en Londres ${ }^{37}$. Como refiere Carrasco Vázquez, un mes después Juan Núñez Saravia tuvo una entrevista privada con Olivares. Nuñez Saravia era un converso de origen portugués que en 1625 había heredado a su tío, Juan Núñez Correa, la dirección de una reputada casa de negocios con actividades comerciales en Brasil, Sevilla, y Asia, y que en Castilla había asumido la gestión de la renta de la avería en años precedentes (1604-1613), y que en 1623 había alcanzado un acuerdo con la Real Hacienda sobre la deuda derivada de este contrato y otros pasivos, que en buena parte accedió a cobrar en vellón. En dicha reunión, el banquero portugués hizo al valido una oferta inicial de crédito con la lista de personas que participarían. Los resultados fueron positivos, pues al poco algunos obtuvieron una licencia real para desplazarse a la Corte y Sevilla (Nuno Dias Mendes de Brito y Duarte Fernandes, respectivamente $)^{38}$. Con ello Olivares mandaba un mensaje tanto a la Inquisición portuguesa, que no tardó en mostrar su inquietud, como a los hombres de negocios genoveses, cuyas exigencias se dejaban notar en la contratación de asientos.

Durante los meses siguientes los gastos militares conllevaron que la firma de empréstitos tuviera que mantener la intensidad de años precedentes. Por otra parte, cuando apenas habían transcurrido unas semanas desde que se había acordado el asiento de provisiones generales para 1626 por importe de 5.980 .000 escudos y ducados, Olivares ya instaba la contratación de nuevos créditos. Tal y como resaltaba el Consejo de Hacienda, las dificultades para encontrar consignaciones, el premio de la plata, y el agotamiento del mercado de juros, empecían las negociaciones y elevaban los costes financieros. Gracias al donativo concedido por las Cortes a comienzos de 1625, a la renovación de los «millones viejos» y a la concesión de un nuevo servicio en febrero de 1626 (12 millones en seis años) se pudo mantener el nivel de gastos, pero la situación crediticia no parecía sostenible a medio plazo ${ }^{39}$.

La colaboración de los «hombres de la nación» se presentaba como una imperiosa necesidad financiera. A comienzos de 1626, un conocido cristiano nuevo portugués con contactos en Lisboa y Brasil arraigado en Amberes desde 1602, Thomé Lopes de Ulloa, había sido nombrado pagador general del ejército de Flandes ${ }^{40}$. Meses después, el 19 de junio, Simón y Lorenzo Pereira, que el año anterior había efectuado el citado asiento, se convirtieron en arrendadores de todas las salinas de Castilla, excepto Galicia y Asturias, por diez años ${ }^{41}$. El camino estaba despejado.

A mediados de julio se requería al presidente del Consejo de Hacienda, Gilimón de la Mota, la negociación de un asiento que añadiera otros 1,5 millones de

37 AGS, Contadurías Generales, leg. 119.

${ }^{38}$ Carrasco Vázquez, "Contrabando, moneda y espionaje”, 1104, y La minoría judeoconversa, 272-275, 280-281; Boyajian, Portuguese bankers, 22-23.

${ }^{39}$ De Carlos Morales, "La política financiera", 1146-1155.

40 Boyajian, Portuguese bankers, 23-24.

41 AGS, CJH, leg. 643, consultas del Consejo de Hacienda, s.f. 
ducados para Flandes, a las cantidades ya aportadas en el asiento de provisiones generales. Su respuesta advertía que la oferta que podría ser asumida por los hombres de negocios genoveses alcanzaría solamente 400.000 escudos para Flandes. El acuerdo estaba a punto de ser aceptado por el Consejo de Hacienda cuando los banqueros portugueses que desde el año antes estaban en la Corte y en Sevilla efectuaron una oferta por similar cantidad, que se distribuiría entre Duarte Fernández, Manuel de Paz y Simón Suárez (200.000 entre los tres) Nuño Díaz Méndez (100.000), Manuel Rodríguez Delvas (50.000), y Juan Núñez Saravia (50.000). Aunque el Consejo valoraba que el asiento ofrecido por los genoveses tenía mejores condiciones para la Real Hacienda, consideraba que la oportunidad resultaba oportuna para decantarse por los portugueses por varios motivos:

La introducción destos hombres en hazer asientos con V.Md. y poner casa de negocios en la corte para este efeto tiene el Consejo por muy conveniente por la conpetencia que podrán hazer a los ginoveses en los asientos y por las comodidades que de los mismos se podrán sacar, si bien el principio que dan a esto con el asiento presente, antes será mal exemplo que bueno para los asientos que adelante se hizieren ${ }^{42}$.

42 AGS, CJH, leg. 621, fajo 15, consultas de 9 y 16 de agosto y oferta del 14, fajo 21, consulta del Consejo de 17 de agosto de 1626, y leg. 622, de 15 de agosto de 1626. Ya hemos manejado esta información y el cuadro que sigue, en "La financiación de Felipe IV", 1160-1162:

\begin{tabular}{|c|c|c|}
\hline & GENOVESES & PORTUGUESES \\
\hline PROVISIÓN & $\begin{array}{l}400.000 \text { escudos de } 57 \text { placas, } \\
\text { tasados a } 402 \text { mrs/escudo }(428.000 \\
\text { dcs), en cuatro pagas mensuales de } \\
100.000 \text { entre octubre y enero. }\end{array}$ & $\begin{array}{l}400.000 \text { escudos de } 57 \\
\text { placas, tasados a } 402 \\
\text { mrs/escudo ( } 428.000 \text { dcs), en } \\
\text { cuatro pagas mensuales de } \\
100.000 \text { entre octubre y enero. }\end{array}$ \\
\hline CONSIGNACIÓN & $\begin{array}{l}\text { Principal de } 600.000 \text { ducados, en } \\
30.000 \text { ducados de renta de juro de } \\
20.000 \text { el millar, situados sobre el nuevo } \\
\text { servicio de millones }\end{array}$ & $\begin{array}{l}\text { Total: } 630.000 \text { ducados, } \\
\text { repartidos entre: } 180.000 \\
\text { ducados en plata en el donativo } \\
\text { (100.000 en octubre, } 50.000 \text { en } \\
\text { noviembre, } 30.000 \text { en } \\
\text { diciembre); y } 450.000 \text { ducados } \\
\text { en los millones nuevos y viejos } \\
\text { de } 1627 .\end{array}$ \\
\hline ADEHALA & $\begin{array}{l}\text { Consumo de } 35.000 \text { ducados de } \\
\text { renta de juros sin cabimiento. } \\
\text { Licencia de saca de } 400.000 \\
\text { escudos. } \\
\text { Beneficio de } 10.391 .500 \mathrm{mrs}\end{array}$ & $\begin{array}{l}\text { Mudanza de } 2.000 \text { ducados } \\
\text { de renta de juros de las alcabalas } \\
\text { sin cabimiento, en alcabalas de } \\
\text { Madrid a Granada } \\
\text { Licencia de saca de } 300.000 \\
\text { ducados. } \\
\text { Beneficio de } 10.312 .500 \mathrm{mrs}\end{array}$ \\
\hline RESGUARDO & & $\begin{array}{l}30.000 \text { ducados de renta de } \\
\text { juro de } 20.000 \text { el millar, situados } \\
\text { sobre el nuevo servicio de } \\
\text { millones. }\end{array}$ \\
\hline
\end{tabular}


No obstante, en el Consejo de Hacienda no había unanimidad, pues veía los inconvenientes que planteaba la consignación del donativo («vaga e incierta») y que la oferta de los genoveses era más consistente. Finalmente, Felipe IV determinó que se firmara el trato con los portugueses y que encargara a la junta del donativo, presidida por el propio Olivares, de su cumplimiento ${ }^{43}$.

De esta manera, con este trato los miembros de ese consorcio abrieron una vía de penetración en la financiación de la Monarquía. Por su parte, los genoveses, a pesar de las dificultades, durante los meses siguientes continuaron asumiendo la contratación de asientos, así que hasta finales de 1626 la Real Hacienda pudo sostener el suministro de fondos para Flandes, Italia y Alemania. Pero la escasez de consignaciones y el aumento de la morosidad en el cumplimiento de los desembolsos (los millones viejos y nuevos resultaban insuficientes por las consignaciones y el situado que soportaban y por la mala gestión del Reino de su recaudación) se agravó con el agotamiento del mercado de juros y el cese de las acuñaciones, demandado por las Cortes para frenar el premio de la plata. La consiguiente disminución de la circulación monetaria anunciaba una contracción crediticia y la necesidad de realizar una reconversión de los pasivos de la Real Hacienda.

Las negociaciones para la contratación del asiento anual de provisiones generales, que habitualmente tenía lugar entre el Consejo de Hacienda y los hombres de negocios genoveses entre diciembre y enero de cada año, no fructificaron. No obstante, en enero se firmaron algunos asientos menores con algunos banqueros genoveses, mientras que, por su parte, los portugueses Nuño Díaz Méndez Brito, Juan Núñez Correa y los hermanos Simón y Lorenzo Pereira, el día 21de enero llegaron a concertar un asiento de 1.500 .000 de escudos para Flandes ${ }^{44}$.

La convergencia de intereses entre Olivares y los banqueros portugueses se completó en los primeros meses de 1627. El 31 de enero se produjo una coincidencia de tres actos que no hubo de ser casual. Por una parte, Felipe IV firmó la primera suspensión de pagos de su reinado, de la que excluía el 31 de enero a diversos acreedores: principalmente los Fugger y, también, ya que la orden afectaba exclusivamente a los asientos suscritos por el Consejo de Hacienda, excusaba a los banqueros portugueses que en octubre se habían comprometido con la junta del donativo ${ }^{45}$.

Por otra parte, al mismo tiempo el rey recibió una consulta de una junta presidida por su confesor y compuesta por otros religiosos, en su mayor parte predicadores, en la que asumían y validaban la plena participación de los cristianos nuevos portugueses en los negocios financieros de la Real Hacienda,

43 AGS, CJH, leg. 621, fajo 21, consulta de 30 de agosto, si bien la fecha oficial del asiento fue el 28 de octubre. El trato, en AGS, CG, leg. 120.

44 AGS, CJH, leg. 632, sin foliar, consultas de 10 y 24 de enero, 8 de marzo y 2 de abril del Consejo de Hacienda. El trato, como más adelante comentaremos, después quedó anulado y asumido en el asiento de provisiones generales. Para estos meses de 1627, de Carlos Morales, "La política financiera", 1162-1164.

45 AGS, CJH, leg. 632. Este documento se analiza y transcribe en de Carlos Morales, El precio del dinero, I, 178-180, y II, 163-164. 
...teniendo consideración al estado en que se halla mi Real Haçienda por las grandes provisiones que continuamente se haçen para aquellos estados, Alemania y otras partes, para que los Assentistas sean más en número y mis vasallos y naturales del dicho Reyno de Portugal se animen a entrar en semexantes asientos ${ }^{46}$.

Finalmente, ese mismo día, Felipe IV remitió al presidente del Consejo de Hacienda, una orden «en favor de los hombres de negocios de Portugal que son de nación hebrea, asentistas con S.M.», en la que garantizaba a «Nuño Díaz Méndez de Brito..., Juan Núñez Saravia, Simón y Lorenzo Pereira, y [¿?] Rodríguez», que las consignaciones, juros de resguardo y otras adehalas que recibieran en pago y satisfacción de sus asientos quedaban exentas de cualquier embargo o confiscación, incluso de la Inquisición. Este privilegio se justificaba citando la referida consulta de la junta presidida por su confesor, e incluía que pudieran traspasar dichos activos libremente y siempre que las sumas comprometidas por cada uno superaran los 100.000 ducados $^{47}$.

Esta vinculación entre prestaciones financieras y relajación de la presión social e inquisitorial sobre los marranos portugueses se prolongó durante los meses siguientes. Tras la suspensión de pagos no tardaron en reanudarse las negociaciones con los hombres de negocios. Desde febrero, los banqueros portugueses se mostraron dispuestos a participar en el asiento de provisiones generales de 1627, que el Consejo de Hacienda estimada que debía alcanzar 4.730 .000 escudos y ducados. El 8 de marzo los portugueses concretaban su oferta: aportarían 1.852 .000 escudos y ducados ${ }^{48}$. La situación no carecía de complejidad. Unos días antes, el 3 de marzo, Olivares había recibido una consulta de una junta compuesta por el confesor fray Antonio de Sotomayor, Francisco de Contreras, el cardenal Trejo y Alonso de Cabrera, advirtiendo de la inconveniencia de proceder a una relajación de los procedimientos inquisitoriales, tal y como se rumoreaba, al tiempo que se negociaba con los cristianos nuevos portugueses $^{49}$.

Si bien los portugueses habían tomado la iniciativa, Olivares no quería ni podía prescindir de los hombres de negocios genoveses y alemanes, si no incentivar la competencia y distribuir el esfuerzo financiero entre todos ellos. Según refirió el embajador florentino, el conde duque se reunió con los tres grupos por separado en

\footnotetext{
${ }^{46}$ Carrasco Vázquez, La minoría judeoconversa, 279, quien se basa en AGS, CJH, leg. 657, s.f. Además del confesor, participaron Jerónimo de Florencia, predicador del Rey y confesor de los infantes; fray Francisco de Jesús, fray Juan de San Agustín, y fray Hernando de Salazar, predicadores del monarca y el último, además, confesor del Conde Duque; y los maestros fray Domingo Cano y fray Diego de Lorenzana, dominicos; y Luis de Torres, jesuita.

${ }^{47} \mathrm{BNE}$, ms. 2311, fol.255 r-v (en parte transcrito por Cohen, "El retorno de los judeoconversos portugueses en época del conde duque de Olivares”, 203-204 (aunque su análisis del contexto resulta contradictorio).

48 AGS, CJH, leg. 638, y leg. 632. Dicha oferta suponía la anulación del asiento de 1,5 millones concertado el 21 de enero, tal y como anotaban los implicados en la oferta de 8 de marzo, en anotación marginal hológrafa del día 14.

49 Pulido Serrano, Injurias a Cristo, 90, con referencia en AHN, leg. 7130, consulta de 3 de marzo.
} 
tres estancias de palacio: la que correspondió a los portugueses contenía uno o varios lienzos sobre la expulsión de los moriscos de 1609, para darles a entender que esta medida podría ampliarse a su minoría religiosa si su contribución no resultaba generosa $^{50}$. La emulación entre banqueros surtió efecto, a pesar de las dificultades las negociaciones fueron cuajando y a primeros de abril ya estaba acordado el asiento de provisiones generales para 1627 con los hombres de negocios, que se repartirían por vía de factoría, 5.014.000 escudos y ducados: los genoveses, 1.892.000; los portugueses, 1.852.000; la casa de los Fugger nuevos, el conde Jerónimo Fúcar, hermanos y primo, representados por Julio César Scuaçola, 600.000 ducados; la casa de los Fugger viejos, los herederos de Marcos y Cristóbal, hermanos, representada por Andreas Hyrus, $670.000 \mathrm{dcs}^{51}$. Las condiciones de la factoría fueron muy similares para los banqueros portugueses y genoveses: administración y control contable, seguridades (en caso de que no recibieran las consignaciones no realizarían las provisiones correspondientes), costes de cobranzas, transporte de moneda, anticipaciones (8\%), y riesgos (del 5 al $3 \%$; licencias de saca, y que la reducción del vellón a plata fuera asumida por cuenta de la Real Hacienda, etc. Además, los portugueses aprovecharon para reclamar las libranzas que se les adeudaban por el asiento de 400.000 escudos tomado el otoño anterior con la junta del donativo.

Por su parte, los hombres de negocios portugueses firmaron los asientos en compañía o por separado, así como las aplicaciones a las que irían destinadas las sumas: Manuel Rodríguez De Elvas, Manuel de Paz, Simón Suárez y Duarte Fernández aportaron entre todos 500.000 escudos para Flandes; Nuño Díaz Méndez allegó otros 500.000 escudos y ducados (166.666,66 escudos para Flandes, 104.000 ducados para la armada, y 360.000 para los extraordinarios de las casas reales, capilla y guardas); Duarte Díaz Enríquez, 180.000 ducados para casas reales, extraordinarios, capilla y guardas; Simón y Lorenzo Pereira, y Juan Núñez Saravia, 541.433 es y dcs $\left({ }^{52}\right)$. Por consiguiente, los portugueses aportaron un millón para Flandes en plata; 312.000 ducados para la Armada (la mitad en plata y en vellón); 360.000 ducados para los gastos ordinarios de las casas reales (28.800 en plata y 331.200 en vellón) y otros 60.000 para extraordinarios (la mitad en cada metal); y 120.000 ducados para capilla y guardas, en vellón. En cuanto a las consignaciones, fueron las siguientes: en la flota de Indias de 1626, 491.334 ds; en la Cruzada de 1627, 163.300 ds; en el servicio de 18 millones 1627, 396.250 ds; en efectos de la factoría de 6 de mayo de 1625, 462.600 ds; en rezagos diversos (millones, servicios ord. y extra., y Excusado), 232.800 ds; en el servicio ord.

${ }^{50}$ Ruiz Martín, Las finanzas de la monarquía, 81-82; y para el escenario, Juan I. Pulido Serrano, "La expulsión frustrada. Proyectos para la erradicación de la herejía judaica en la Monarquía Hispana”, en La Declinación de la Monarquía Hispánica en el siglo XVII, coord. Francisco J. Aranda Pérez, (Cuenca, 2004), 891-892.

51 AGS, CJH, leg. 632, consulta de 2 de abril, y leg. 638; CG, leg. 121. En total pues, se trataba de una provisión de 2.623.000 escudos (en oro o plata), 738.000 ducados en reales de plata y 1.646.000 ducados en moneda de vellón. En cuanto a las consignaciones, gravaban rentas castellanas por importe de 5.892.607 ducados en plata y vellón, según la renta. Véase, de Carlos Morales, "La política financiera", 1169-1171.

${ }^{52}$ AGS, CJH, leg. 632, consulta de 2 de abril, y CG, leg. 121, fechados a 11 de junio. 
y extr. de 1627, 185.154 ds; Excusado, 108.000 ds; y en el servicio de 12 millones de 1627, 120.000 ds. En total, pues, 2.159.438 ducados.

La fecha oficial de firma fue el 11 de junio. Los destinos de las aportaciones y las consignaciones recibidas en pago demuestran la plena implicación de los portugueses en la superación de la crisis financiera de 1627. Al cabo de unos días, el 21 de junio, Felipe IV firmó un Edicto de Gracia de tres meses para que los cristianos nuevos portugueses pudieran confesar sin castigo los delitos de fe que hubiesen cometido. Unos meses después, este edicto se completaba el 7 de agosto, con un mandato del rey para que no se efectuaran confiscaciones de bienes a los conversos que acudiesen al Santo Oficio motu propio a declarar sus errores. El edicto de gracia se publicó el 19 de septiembre tanto en los tribunales de la Inquisición portuguesa como de la española, y al cabo se amplió por otros tres meses ${ }^{53}$. Se trataba de una garantía tanto para los judeoconversos portugueses como para las operaciones de financiación que suscribiesen con la Real Hacienda, ya que los asientos se basaban en una red de contactos crediticios que implicaban a diversos agentes y casas mercantiles.

\section{CONCLUSIONES: INCENTIVOS Y MOTIVACIONES EN UNA RELACIÓN MULTIFACTORIAL}

A finales de 1627 la Real Hacienda parecía haber superado, no sin costes, los graves problemas derivados del incremento del gasto dinástico emprendido en 1618. Felipe IV disponía, por una parte, de una nueva fuente crediticia con la incorporación de los hombres de negocios portugueses; por otra, había concertado el medio general con los hombres de negocios genoveses; y, finalmente, contaba con la renovación de los servicios de millones, que se habían convertido en su ingreso más importante en vellón, y que además soportaba un situado en concepto de juros creados en 1626 y entregados en pago conforme al medio general.

Como muestra de esta recuperación financiera, entre finales de 1627 y marzo de 1628 se concertaron varios asientos para satisfacer las provisiones generales por un montante de casi cinco millones y medio de escudos y ducados. A finales de diciembre de 1627 se comenzó a negociar la parte correspondiente a los banqueros portugueses, que se repartirían 1.000.000 de escudos destinados a Flandes (en oro o plata), y 300.000 ducados a la Armada del Mar Océano (por mitades, en plata y vellón). El reparto de las provisiones fue proporcional entre Simón y Lorenzo Pereira, Simón Suares, Juan Núñez Saravia, Duarte Fernández, Nuño Díaz Méndez de Brito, y Manuel de Paz, que tocaron respectivamente a 185.714 y $2 / 7(142.857$ y $1 / 7$ es. para Flandes y 42.857 y $1 / 7$ ds en Sevilla o la corte); por su parte, Manuel Rodríguez de Elvas y Duarte Díaz Enríquez asumieron cada uno, 92.857 y $1 / 7$ (71.428 y 4/7 es para Flandes y 21.428 y $4 / 7$ ds en Sevilla o la corte), 92.857 y 1/7. Las consignaciones también estaban distribuidas proporcionalmente: tras sumar un $8 \%$ de interés, y contar los escudos de

53 Para estas y posteriores disposiciones, Domínguez Ortiz, Política y Hacienda, 124-125, Pulido Serrano, Injurias a Cristo, 90-105. 
Flandes a $398 \mathrm{mrs}$, montaban $562.828 .000 \mathrm{mrs}$ (1.500.875 dcs), que recayeron sobre la flota llegada a Sevilla (125 cuentos), la Cruzada de 1628 (49.000.000 mrs), la «unión de los reinos» (42.500.000 mrs), rezagos de millones y alcances $(37.500 .000 \mathrm{mrs})$, la corte (115.083.400 mrs), los servicios de 18 y 12 millones (68.750.000 mrs y $50.000 .000 \mathrm{mrs}$, respectivamente); y, finalmente, unos 75 cuentos sobre renta de alcabalas y juros que podían enajenar. Seguridades, anticipaciones y socorros de libranzas, licencias de saca, jueces privativos y exenciones completaban el conjunto de ganancias que los portugueses obtendrían en concepto de adehalas ${ }^{54}$.

La fecha de firma de este trato financiero dividido en ocho asientos fue el 11 de marzo de 1628. Justamente, ese mismo día, un nuevo decreto de Felipe IV satisfizo diversas demandas efectuadas desde años atrás por los conversos portugueses, que aliviaban los procedimientos inquisitoriales y mejoraban sus condiciones de vida, como la obtención de la posibilidad de matrimonios mixtos. Unos meses después la participación de los portugueses en las provisiones generales se ampliaba con otro asiento tomado con Duarte Fernández y Manuel de Paz, por el que añadían 33.333,3 escudos para Flandes ${ }^{55}$.

Ambos, Duarte Fernández y Manuel de Paz, se mantuvieron en la cúspide de la contratación durante dos décadas; mientras, los demás portugueses que se habían iniciado en la contratación en 1626 y 1627, participaron solamente unos años: Nuño Díaz Méndez de Brito, hasta su muerte en Madrid en 1628; Manuel Rodríguez de Elvas, hasta 1629; Joao Nuñes Saravia, hasta su procesamiento inquisitorial en 1631; y Simao Soares, hasta su muerte en 1633. Gradualmente se fueron incorporando otros importantes hombres de negocios, como Duarte Díaz Enríquez en 1627-28, García de Yllán, en 1629, y Jorge de Paz Silveira, en $1632^{56}$.

Con los años, la penetración de los portugueses tanto en las finanzas como en los arrendamientos de rentas se fue ampliando ${ }^{57}$. Su establecimiento en la corte, en Sevilla y en otros enclaves había quedado facilitado por las medidas señaladas, a las que hay que añadir, el 17 de noviembre de 1629, la obtención de la libertad de movimientos a los conversos lusos a cambio de un donativo de 250.000 cruzados. No obstante, señala Pulido Serrano que dichas disposiciones no significaron una mejora para la situación de los judeoconversos portugueses dado que la Inquisición lusa no relajó su actuación; sin embargo, la entrada de individuos de esta comunidad en la Corona de Castilla aumentó de nuevo desde entonces ${ }^{58}$.

54 AGS, CJH, leg. 643, consultas de 26 de diciembre de 1627 y 23 de febrero de 1628; CG, leg. 122.

55 AGS, CG, leg. 122, fechado el 24 de mayo, tasados a 399 mrs cada escudo suponían 13.266.666 mrs a consignar, con un interés del $8 \%$ en beneficio de la Real Hacienda, ya que debían cobrar en mayo (sobre el donativo) y efectuar los pagos en Flandes en 8 pagas hasta diciembre.

${ }^{56}$ Datos sobre la participación en el primer periodo, entre 1626 y 1632, Boyajian, 28-30, 206-211, Carrasco Vázquez, 285-294. Para García de Yllán, Ebben, Zilver, Brood en Kogels, 149-158, y "Corona y comerciantes: García de Yllán, un mercader al servicio de Felipe IV”, en Diálogos Hispánicos 16 (1995): 169-186. Por su parte, Sanz Ayán, Los banqueros y la crisis, 239-347, para Duarte Fernández, y 254-255, para Manuel de Paz.

${ }^{57}$ Caro Baroja, "La sociedad criptojudía”, 99-113, Domínguez Ortiz, Política y Hacienda, 199-215.

58 Pulido Serrano, Injurias a Cristo, 100-108. 
Cabe suponer que, además de motivaciones socio-religiosas, otras circunstancias habían inducido a los banqueros a colaborar con la financiación de los gastos dinásticos de Felipe IV. Ciertamente, por entonces el "camino español" de ferias, plazas y letras de cambio que desde el reinado de Felipe II había estado funcionando entre Italia y Flandes se encontraba con serios obstáculos, como la crisis de las ferias genovesas desde 1623, que hacían más viable y cómoda otra vía que conectaba a los banqueros portugueses con Ámsterdam, vía Londres, y con otras plazas con presencia sefardita ${ }^{59}$. En esta posición internacional radicaba su fuerza en la corte de Felipe IV, como revelaban las propias denuncias de autores antisemitas como Quevedo:

Siendo verdad infalible que todos los judíos de España consisten para los asientos en dos cosas, que son caudal pronto y crédito puntual: con el caudal trajinan y negocian, con el crédito socorren. El caudal, como siempre le tienen sus pecados, temeroso del Santo Oficio y amenazado de confiscaciones, consiste en moneda y mercancías portátiles y siempre dispuestas a la fuga. El crédito le tienen en Raguza, en Salónique, en Ruán, en Ámsterdam, de manera que dependen para toda la puntualidad y aceptación de sus letras de los que son enemigos de V. M. Pues si son para Flandes, contra los herejes rebeldes, depende dellos propios la paga; si contra los turcos, depende de los propios turcos; si contra los franceses, depende de los franceses; si contra los herejes de Alemania, depende de los mismos herejes la judería de Praga; y si se encendiese guerra en Italia, dependerá de las sinagogas de Roma y Ligorna y Venecia. V. M. sabe si será necesario prevenir esto, pues si se presumiesen rumores entre las armas de V. M. y algunos potentados, podrían estos asentistas judíos ser desde Vuestra corte la mejor parte de sus ejércitos ${ }^{60}$.

Para la Monarquía Católica, la colaboración de los hombres de negocios portugueses permitió superar uno de los obstáculos más relevantes que afrontaba el cumplimiento del gasto dinástico exterior: la consecución de plata para el pago de las tropas de Flandes; así, el esfuerzo pudo mantenerse e incrementarse en volumen y destino ${ }^{61}$. De esta manera, a modo de conclusión, podemos afirmar que su

${ }^{59}$ Ruiz Martín, La financiación, 86-94; Claudio Marsilio, “Cumplir con cuidado. Il mercato del crédito genovese negli anni 1630-1640. Vecchi protagonista e nuove strategie operative", en Génova y la Monarquía hispánica (1528-1713), coords. Manuel Herrero et allii, (Génova, 2011), 801-818, Daviken Studnicki-Gizbert, $A$ nation upon the ocean sea, especialmente 91-121, para las redes comerciales, y 151174, para los judeoconversos.

${ }^{60} \mathrm{~F}$. de Quevedo, Execración por la fe católica contra la blasfema obstinación de los judios que hablan portugués y en Madrid fijaron los carteles sacrílegos y heréticos, aconsejando el remedio que ataje lo que, sucedido, en este mundo con todos los tormentos aun no se puede empezar a castigar, (Madrid, 1633). Edición, prólogo y notas de Fernando Cabo Aseguinolaza y Santiago Fernández Mosquera (Barcelona: Crítica, 1996), 79-80.

${ }^{61}$ Una comparativa respecto a genoveses y alemanes, Alberto Marcos Martín, "España y Flandes (1618-1648): la financiación de la guerra”, en Calderón de la Barca y la España del Barroco. II, coords. José Alcalá-Zamora y E. Belenguer, (Madrid, 2001), 18-39. La tendencia de las provisiones no experimentó cambios significativos entre 1621-25 y 1626-30, ni en cuanto al volumen, ni en cuanto al destino, pues si Italia abrió una nueva espita de gasto desde 1628, su financiación no se efectuó en detrimento del gasto militar de los Países Bajos soportado por la Real Hacienda castellana. Del total de asientos estimado por el profesor Marcos para 1628 las provisiones de Flandes supusieron en torno al 50 \%, cifra similar a la de años anteriores, aportada por los genoveses en un $68,4 \%$. Habría de ser a partir de 
participación en las finanzas de Felipe IV tuvo una doble dimensión estrechamente relacionada.

Por una parte, debe situarse en la evolución de la economía castellana y de los procedimientos de financiación de la Real Hacienda. Los hombres de negocios portugueses cobraban en Castilla en moneda de vellón la recaudación de los millones consignados en los asientos y otras rentas que arrendaban, réditos de juros, y otros efectos, e invertían estos ingresos en lana y otras materias primas que podían vender en el exterior en moneda de plata. Tal y como ha sido advertido por diversos investigadores, la creciente dependencia del crédito y de la fiscalidad indirecta se tradujo en una transferencia y privatización de competencias de los espacios fiscofinancieros castellanos hacia los hombres de negocios genoveses y portugueses, que se intensificó a causa del esfuerzo provocado por la Guerra de los Treinta Años; en una reciente ocasión, hemos señalado que este proceso puede interpretarse con dos conceptos, financial devolution y taxes by contract $f^{22}$.

Por otra parte, a través de las consignaciones establecidas en los asientos recibían la plata que llegaba a la Casa de la Contratación (o vía contrabando), que podían emplear directamente para sus negociaciones intercontinentales. De esta manera los banqueros portugueses dispusieron de varios stocks de capital en Europa que les dotaron de una posición relevante en la economía atlántica, al hacer circular la plata entre las principales plazas financieras y mercantiles internacionales ${ }^{63}$. Así, la compleja colaboración entre la Real Hacienda y los hombres de negocios «de la nación hebrea» en tiempos de Felipe IV podría considerarse como una vertiente dentro de ese proceso de expansión de la economía mundo que ha sido pomposamente rebautizado como primera globalización ${ }^{64}$, en el que la Monarquía Católica, en lugar de ocupar un papel secundario o periférico, tal y como tanto la bibliografía tradicional como la más reciente afirman (al asociarla con la tópica decadencia del Imperio español), desempeñó una posición singular en cuanto potencia imperial ${ }^{65}$.

1629 cuando la participación de los banqueros ligures en la financiación de la guerra de los Países Bajos se redujera hasta el 31,9\%, y esto significó el incremento de la participación de los portugueses en los asientos de Flandes (el 31,6 \% en 1628 y el 46,3 \% en 1629, mientras que los alemanes contaron con el $21,8 \%$ en 1629).

62 Para estos conceptos, que aquí no podemos desarrollar, Carlos Javier de Carlos Morales, "Financiando la Guerra de los Treinta Años: gasto bélico, endeudamiento y financial devolution", en Manuscrits. Revista d'Història moderna 38 (2018): 109-138.

${ }^{63}$ Además de las referencias citadas previamente, en particular, Claudio Marsilio, "The Genoese and Portuguese Financial Operators Control of the Spanish Silver Market (1627-1657)", en Journal of European Economic History, 41-3 (2012): 69-89 y "Which way to turn?" The destinations of the Spanish silver (1621-1650) London, Lisbon, or Genoa?”, DT/WP 54, (Universidad de Lisboa, 2015).

${ }^{64}$ Para este discutido concepto existe una amplia historiografía. Por apuntar algún título, Kenneth Pomeranz y Steven Topik, The World That Trade Created: Society, Culture and the World Economy, 1400 to the Present, (Nueva York, 1999), M.D. Bordo, A. M. Taylor y J. G. Williamson (eds.), Globalization in Historical Perspective, (Chicago U. Press, 2003); Robbie Robertson, Tres olas de globalización: historia de una conciencia global, (Madrid, 2005); Charles H. Parker, Global Interactions in the Early Modern Age, 1400-1800, (Cambridge UP, 2010).

${ }^{65}$ Véase, Bartolomé Yun Casalilla, Iberian World Empires and the Globalization of Europa, 1415-1668 (Singapur: Palgrave Macmillan, 2019). 


\section{FUENTES BIBLIOGRÁFICAS}

Adler, Elkan N., "Documents sur les marranes d' Espagne et de Portugal sous Philippe IV”, en Revue des études juives, 48 (1904), 49 (1905) y 50 (1905).

Álvarez Nogal, Carlos, Los banqueros de Felipe IV y los metales preciosos americanos (16211665), (Madrid, 1997), 89-108.

Bordo, M. D., Taylor, A. M. y Williamson, J. G. (eds.), Globalization in Historical Perspective, (Chicago U. https://doi.org/10.7208/chicago/9780226065991.001.0001

Boyajian, James C., The Portuguese Bankers and the International Payments Mechanism, 16261647, (Berkeley, 1978).

Boyajian, James C., Portuguese bankers at the court of Spain, 1620-1650, (New Brunswick, 1983).

Boyajian, James C., Portuguese Trade in Asia Under the Habsburgs, 1580-1640, (Baltimore, 1993).

Broens, Nicolas, Monarquia y capital mercantil: Felipe IV y las redes comerciales portuguesas (1627-1635) (Madrid: Universidad Autónoma de Madrid, 1989).

Cañas Pelayo, Marcos Rafael, "Los judeoconversos portugueses de la edad moderna en la historiografía española: un estado de la cuestión", en Revista de Historiografía 23 (2015): 217-243.

Cañas Pelayo, Marcos Rafael, Los judeoconversos portugueses en el Tribunal Inquisitorial de Córdoba: Un análisis social (ss. XVI-XVII) (Tesis doctoral en acceso abierto, (Universidad de Córdoba, 2016).

Carlos Morales, Carlos Javier de, El precio del dinero dinástico: endendamiento y crisis financieras en la España de los Austrias, 1557-1647, 2 vols., (Madrid, 2016).

Carlos Morales, Carlos Javier de, "La política financiera de Felipe IV, 1621-1628", en La Corte de Felipe IV (1621-1665). Reconfiguración de la Monarquía católica. III. El sistema de corte. Consejos y Hacienda, 4 vols., José Martínez Millán y Manuel Rivero, (Madrid, 2017), vol. 2, 1099-1212.

Carlos Morales, Carlos Javier de, "Financiando la Guerra de los Treinta Años: gasto bélico, endeudamiento dinástico y financial devolution", en Manuscrits (2018), en prensa. 
Caro Baroja, Julio, Los judios en la España moderna y contemporánea, 3 vols. (Madrid: Arión, 1961-1962; $3^{a}$ edición, Madrid: Itsmo, 1986).

Caro Baroja, Julio, La sociedad criptojudia en la Corte de Felipe IV (Madrid, 1963; versión publicada en Inquisición, brujería y criptojudaísmo, Madrid: Ariel, 1974), 11-180.

Carrasco Vázquez, Jesús, “Contrabando, moneda y espionaje (el negocio del vellón (1606-1620)", en Hispania 197 (1997): 1081-1105. https://doi.org/10.3989/hispania.1997.v57.i197.678

Carrasco Vázquez, Jesús, La minoría judeoconversa en la época del conde duque de Olivares. Auge y ocaso de Juan Núñez. Saravia (1585-1639), Tesis doctoral (en acceso abierto) (Universidad de Alcalá, 2004).

Carrasco Vázquez, Jesús, "El relevante papel económico de los conversos portugueses en la privanza del duque de Lerma 1600-1606", comunicación presentada al XXV Encontro da APHES, Évora 10-19 de noviembre de 2005.

Cohen, Shai, "Los banqueros portugueses, potestad económica versus autoridad divina", en El universo simbólico del poder en el Siglo de Oro, eds. Á. Baraibar y M. Insúa, (Univ. de Navarra, 2012), 51-63.

Cohen, Shai, "El retorno de los judeoconversos portugueses en época del conde duque de Olivares", en Hipogrifo: Revista de Literatura y Cultura del Siglo de Oro, vol-extr. 1 (2018): 191-215. https://doi.org/10.13035/H.2018.extra01.14

Contreras Contreras, Jaime, "Domínguez Ortiz y la historiografía sobre judeoconversos", en Manuscrits 14 (1996): 59-80.

Diago Hernando, Máximo, "La irrupción de los conversos portugueses en el comercio de exportación de lanas de la Corona de Castilla en el tránsito del siglo XVI al XVII", en Sefarad 70:2, (julio-diciembre 2010): 399-434.

Domínguez Ortiz, Antonio, La clase social de los conversos en Castilla en la Edad Moderna, (Madrid, 1955).

Domínguez Ortiz, Antonio, Política y Hacienda de Felipe IV, (Madrid: Pegaso, 1960).

Domínguez Ortiz, Antonio, Los judeoconversos en Españay América, (Madrid: Istmo, 1971).

Ebben, Maurits, "Un triángulo imposible: la Corona española, el Santo Oficio y los banqueros portugueses, 1627-1655", en Hispania, 184 (1993): 541-556. 
Ebben, Maurits, Zilver, brood en kogels voor de Koning. Kredietverlening door Portugese bankiers aan de Spanase Kron 1621-1665, (Leiden, 1996).

Ebben, Maurits, "Corona y comerciantes: García de Yllán, un mercader al servicio de Felipe IV”, en Diálogos Hispánicos 16 (1995): 169-186.

García Puente, Roberto, "Colaboración e intereses entre la monarquía de Felipe IV y los hombres de negocios de la nación portuguesa Jorge de Paz Silveira y Pedro de Baeza", en Familia, Cultura Materialy Formas de Poder en la España Moderna, ed. Máximo García Fernández, (Madrid, 2016), 1191-1199.

Hernández Casado, Cristina, "El negocio de los asientos: Jorge de Paz Silveira, financiero portugués al servicio de Felipe IV”, en Monarquias en conflicto. Linajes y noblezas en la articulación de la monarquía hispánica, coords., José I. Fortea Pérez et allii, (Madrid, 2018), 441-450.

Huerga Criado, Pilar, Manuel Enríquez: Un cristiano nuevo entre los poderosos, (Ciudad Rodrigo, 2001).

Israel, Jonathan, "Manuel López Pereyra of Amsterdam, Antwerp and Madrid: jew, nee Christian, and advisor to the conde-duque of Olivares", en Studia Rosenthaliana XIX-1 (1985): 109-126.

Israel, Jonathan, La judería europea en la era del mercantilismo (1550-1750), (Madrid, 1992).

López Belinchón, Bernardo, "Olivares contra los portugueses. Inquisición, conversos y guerra económica”, en Historia de la Inquisición en España y América, 3 vols., J. Pérez Villanueva y B. Escandell Bonet, (Madrid, 2000), III, 499-530.

López Belinchón, Bernardo, Honra, libertad y hacienda (bombres de negocios y judíos sefardíes), (Madrid, 2001).

López Belinchón, Bernardo, "Sacar la sustancia del reino. Comercio, contrabando y conversos portugueses, 1621-1640", en Hispania 209 (2001): 1017-1050. https://doi.org/10.3989/hispania.2001.v61.i209.287

López-Salazar Codes, Ana Isabel, Inquisición portuguesa y monarquía hispánica en tiempos del perdón general de 1605, (Évora, 2016).

Marcos Martín, Alberto, “España y Flandes (1618-1648): la financiación de la guerra”, en Calderón de la Barca y la España del Barroco. II, coords. José Alcalá-Zamora y E. Belenguer, (Madrid, 2001), 18-39. 
Marsilio, Claudio, "Cumplir con cuidado. Il mercato del crédito genovese negli anni 1630-1640. Vecchi protagonista e nuove strategie operative", en Génova y la Monarquia hispánica (1528-1713), coords. Manuel Herrero et allii, (Génova, 2011), 801-818.

Marsilio, Claudio, "The Genoese and Portuguese Financial Operators Control of the Spanish Silver Market (1627-1657)", en Journal of European Economic History, 413 (2012): 69-89.

Marsilio, Claudio, "Which way to turn? The destinations of the Spanish silver (16211650) London, Lisbon, or Genoa?”, DT/WP 54, (Universidad de Lisboa, 2015).

Parker, Charles H., Global Interactions in the Early Modern Age, 1400-1800, (Cambridge UP, 2010). https://doi.org/10.1017/CBO9780511780851

Pomeranz, Kenneth y Topik, Steven, The World That Trade Created: Society, Culture and the World Economy, 1400 to the Present, (Nueva York, 1999).

Pulido Serrano, Juan I., Injurias a Cristo. Religión, política y antijudaísmo en el siglo XVII (Madrid, 2002).

Pulido Serrano, Juan I., Los conversos en España y Portugal,(Madrid, 2003).

Pulido Serrano, Juan I., "Antonio Domínguez Ortiz y el problema converso en su obra", en Historia Social, 47 (2003): 53-69.

Pulido Serrano, Juan I., "La expulsión frustrada. Proyectos para la erradicación de la herejía judaica en la Monarquía Hispana", en La Declinación de la Monarquía Hispánica en el siglo XVII, coord. Aranda Pérez, Francisco J., (Cuenca, 2004), 891-892.

Pulido Serrano, Juan I., "Los judíos en la obra de Julio Caro Baroja”, en Historia Social, 55 (2006): 45-60.

Pulido Serrano, Juan I., "Las negociaciones con los cristianos nuevos en tiempos de Felipe III a la luz de algunos documentos inéditos (1598-1607)", en Sefarad 662 (julio-diciembre 2006): 345-376. https://doi.org/10.3989/sefarad.2006.v66.i2.414

Pulido Serrano, Juan I., "El tiempo de los portugueses. Cristianos nuevos, judaizantes e inquisición (siglos XVI-XVII)", en La inquisición: viejos temas, nuevas lecturas, coords. Manuel Peña Díaz y Jaqueline Vassallo, (Córdoba, 2015), 233-253. 
Quevedo, Francisco de, Execración por la fe católica contra la blasfema obstinación de los judios que hablan portugués y en Madrid fijaron los carteles sacrílegos y beréticos, aconsejando el remedio que ataje lo que, sucedido, en este mundo con todos los tormentos aun no se puede empezar a castigar, (Madrid, 1633). Edición, prólogo y notas de Fernando Cabo Aseguinolaza y Santiago Fernández Mosquera, (Barcelona: Crítica, 1996).

Robertson, Robbie, Tres olas de globalización: historia de una conciencia global, (Madrid, 2005).

Ruiz Martín, Felipe, "La banca en España hasta 1782", en El Banco de España. Una bistoria económica, (Madrid, 1970).

Ruiz Martín, Felipe, Las finanzas de la monarquía bispánica en tiempos de Felipe IV, (Madrid, 1990).

Sánchez Durán, Álvaro, "Los hombres de negocios portugueses: una élite profesional en la Castilla del siglo XVII. Posibilidades de movilidad social e intermediación”, en Tiempos modernos, 31 (2015/2): 193-220.

Sánchez Durán, Álvaro, "Información y reputación en el siglo XVII: la construcción de la confianza en redes sociales de hombres de negocios portugueses", en Studia histórica. Historia moderna, 38-2 (2016): 425-466. https://doi.org/10.14201/shhmo2016382425466

Sánchez Durán, Álvaro, "El crédito portugués en la Monarquía Hispánica de Felipe IV: los asientos de la familia Núñez-Mercado (1640-1652)", en Cuadernos de historia moderna 42, 1, (2017): 57-86. https://doi.org/10.5209/CHMO.56654

Sánchez Durán, Álvaro, "Familia, parentesco y estrategias matrimoniales: hombres de negocios de la nación portuguesa en la corona de Castilla (siglo XVII)", en Nuevas perspectivas de investigación en Historia Moderna: Economía, Sociedad, Política y Cultura en el Mundo Hispánico, eds. Mª Ángeles Pérez Samper y José L. Betrán Moya, (Madrid, 2018).

Sánchez Durán, Álvaro, "Imbricaciones entre lo público y lo privado en la gestión de la Real Hacienda de Felipe IV: hombres de negocios portugueses y ministros reales", en Palacios, plazas, patíbulos. La sociedad española moderna entre el cambio y las resistencias, James Amelang et allii, (Valencia, 2018), 447-460.

Sanz Ayán, Carmen, Los banqueros de Carlos II, (Madrid, 1988).

Sanz Ayán, Carmen, "Las finanzas de la Monarquía y los banqueros judeoconversos. Una aproximación a los sistemas ordinarios de financiación de la corona en el reinado de Felipe IV", en Xudeus e conversos na historia. 2 vols, ed. C. Barros, (Santiago de Compostela, 1994), II, 185-200. 
Sanz Ayán, Carmen, Los banqueros y la crisis de la Monarquía bispánica de 1640, (Madrid, 2013).

Studnicki-Gizbert, Daviken, A nation upon the ocean sea Portugal's Atlantic diaspora and the crisis of the Spanish Empire, 1492-1640, (Oxford-New York: Oxford UP, 2007). https://doi.org/10.1093/acprof:oso/9780195175691.001.0001

Wachtel, Nathan, “The 'Marrano' Mercantilist Theory of Duarte Gomes Solis”, en The Jewish Quarterly Review, 101-2 (2011), 164-188. https://doi.org/10.1353/jqr.2011.0017

Yerushalmi, Yosef Hayin, De la Corte española al gueto italiano. Marranismo y judaísmo en la España del siglo XVII. El caso Isaac Cardoso, (Madrid, 1971; 2ª ed., Madrid: Turner, 1989).

Yun Casalilla, Bartolomé, Iberian World Empires and the Globalization of Europa, 1415-1668 (Singapur: Palgrave Macmillan, 2019). https://doi.org/10.1007/978-981-13$\underline{0833-8}$

Recibido: 4 de junio de 2019 Aprobado: 20 de octubre de 2019 